At the end of the scan the individual counting rates from each detector viewing the "hot" region indicate whether the placenta was anterior or posterior.

\section{Results}

The indications for placentography were a suspicion of placenta praevia in 58 patients who presented with antepartum haemorrhage (52) or a persistent unstable lie at 37 weeks (6) (see Table), and the need to define the placenta before amniocentesis in four. The usual gestation period at which the test was performed was 32-33 weeks, but satisfactory results were obtained as early as 30 weeks. In four patients placenta praevia diagnosed on scanning was not confirmed clinically. These false-positive results were due mainly to overcautious assessment of the scans early in the series, and with experience it has been possible to increase the accuracy of prediction. Of 42 patients with antepartum haemorrhage 32 were allowed home for intervals of two to six weeks after placentography had indicated that the placenta was in the upper uterine segment; no foetal loss resulted.

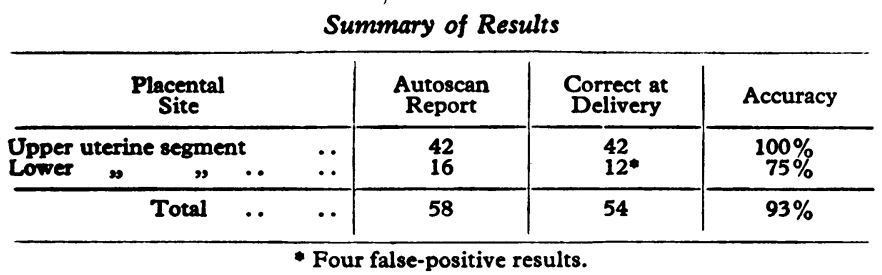

\section{Discussion}

Clinical Applications.-The accuracy of the method described is $93 \%$, and is comparable to that of other reported isotope techniques; its main clinical value is the exclusion of placenta praevia before allowing the patient home for part or all of the remainder of the antenatal period, and it is important in this connexion to note that in no patient was a placenta praevia missed. In this way we calculate that the equivalent of three out of 100 hospital beds a year are released for other purposes. No attempt was made to estimate the degree of placenta praevia, as all cases carry the risk of further possible severe haemor- rhage, and are therefore kept in hospital until after delivery. The other application of the procedure is before amniocentesis, when there is clinical evidence of an anteriorly placed placenta. Here the scan is useful in the selection of a suitable puncture site.

Choice of Isotope.-Albumin tagged with ${ }^{131}$ I was chosen as the most suitable tracer material, because it has been successfully used elsewhere for placental location (Weinberg et al., 1957 ; Heagy and Swartz, 1961 ; Durfee and Howieson, 1962), its biological characteristics are fully known, its production is reliable, it is relatively cheap, and it is readily obtained commercially. Isotopes such as ${ }^{132} I$ and technetium $99 \mathrm{~m}$ have the advantage of a much shorter half-life, so that larger quantities of radioactive material can be used, resulting in higher counting rates and better discrimination. If, however, the facilities required for routine production of albumin tagged with these isotopes are not available ${ }^{131} \mathrm{I}$ albumin has been shown to give satisfactory results.

\section{Summary}

A technique of isotope placental location is described which uses ${ }^{131}$ I and a colour autoscan apparatus. The use of a twocollimator modification has been found to increase the definition of this method, so that the readily available albumin-tagged ${ }^{131} I$ gave satisfactory results.

The accuracy of the method was $93 \%$; no placenta praevia remained undetected.

We are indebted to the consultant staff of the Royal Maternity Hospital, Belfast, for permitting us to include their patients in this study. Our thanks are also due to Dr. R. Ferguson and Dr. W. B. Sproule for their help.

\section{REFERENCES}

Cavanagh, D., Powe, C. E., and Gilson, A. J. (1961). Obstet. and Gynec.,

18, 403 . 577.

Heagy, F. C., and Swartz, D. P. (1961). Radiology, 76, 936.

Hibbard, B. M. (1966). Clin Obstet. Gynec., 9, 93.

McGee, J., and Duron, D. (1960). Obstet. and Gynec., 15, 643.

Weinberg, -A., Rizzi, J., McManus, R., and Rivera, J.' (1957). Ibid., 9. 692.

\title{
Adrenocorticotrophic Action of Long-acting Tetracosactrin Compared with Corticotrophin-gel
}

\author{
G. M. BESSER,* M.D., B.SC., M.R.C.P. ; P. W. P. BUTLER,* M.B., B.S., M.R.C.P. \\ F. S. PLUMPTON, $†$ B.M., B.CH., F.F.A. R.C.S.
}

Brit. med. F., 1967, 4, 391-394

Tetracosactrin ( $\beta^{1-24}$ corticotrophin, Synacthen) is a synthetic polypeptide containing the first 24 amino-acids found in naturally occurring corticotrophin (A.C.T.H.). It has a high degree of corticotrophic activity (Landon et al., 1964) and is used to test adrenocortical responsiveness (Wood et al., 1965). However, since its action lasts only three to four hours after an intramuscular dose (Landon et al., 1964), unmodified tetracosactrin can have little place in therapy. A long-acting version of this compound might offer practical advantages over naturally occurring corticotrophin, particularly in patients who develop hypersensitivity reactions or antibodies to natural corticotrophin, since its amino-acid sequence is identical with that of

- Medical Professorial Unit, St. Bartholomew's Hospital, London E.C.1. + Department of Anaesthesia, St. Bartholomew's Hospital, London E.C.1. the active portion of human corticotrophin and the preparation does not contain any animal contamination. Tetracosactrin has now been modified by adsorption on to an inorganic zinc complex to prolong its action. This paper reports a comparison of its adrenocorticotrophic properties and length of action compared with corticotrophin-gel of animal origin in normal subjects and in patients previously treated with oral corticosteroids or corticotrophin.

\section{Methods and Subjects}

Subjects.-All subjects were volunteers without evidence of endocrine, renal, or liver disease. There were 18 non-steroidtreated subjects, of whom eight were ambulant medical staff, 
four were inpatients who did not require corticosteroid therapy, and six were patients in whom corticosteroid therapy was indicated by the severity of their underlying disease. In the steroidtreated group there were six patients treated with prednisolone for more than three months (range 4 to 12 months) and six treated for less than three months ( 1 to 10 weeks). The dose varied from 10 to $60 \mathrm{mg}$./day. The six corticotrophin-treated subjects had received 40-80 units of corticotrophin-gel daily for one to three weeks, and the injections were stopped 48 hours before the test.

Trial Design and Analysis.-There were three treatments-1 and $2 \mathrm{mg}$. of depot-tetracosactrin, and 80 units of corticotrophin-gel (Armour) of a single batch number (MB 0802). The treatments were given intramuscularly at 72-hour intervals between 9 and 10 a.m. and the order of administration was randomized and balanced among the subjects by means of orthogonal latin square designs. Plasma cortisol estimations were performed at $0,2,4,8,12,24,32,48$, and 72 hours after drug administration. The changes in plasma cortisol were initially analysed by the method of analysis of variance (Snedecor, 1956), and the differences between the means at each time were tested by Hartley's (1955) modification of Student's $t$ test.

Plasma Cortisol Assay.-Plasma 11-hydroxycorticosteroids were measured by the fluorimetric method of Mattingly (1962). This measures principally cortisol (hydrocortisone), as well as small amounts of circulating corticosterone and some other unknown fluorescent substances. The combination is referred to as "plasma cortisol" in this paper.

\section{Results}

Initially results from the patients requiring corticosteroid therapy were analysed separately from those from the other normal subjects, as they were somewhat stressed and might have given different responses. Their results were subsequently combined, since there were no significant differences between the responses of the two subgroups and their variances were homogeneous. This whole group is referred to as " normal subjects." The two groups of corticosteroid-treated patients were also combined in the final analysis, as their responses and variances were not significantly different.

\section{Normal Subjects (Fig. 1)}

The mean plasma cortisol levels after the three treatments were not significantly different at 0,2 , and 4 hours, rising to over three times the resting concentration during this time. After 80 units of corticotrophin-gel the mean level rose further to a maximum of $69 \mu \mathrm{g} . / 100 \mathrm{ml}$. at eight hours, and then fell off rapidly to reach basal levels by 24 hours. After $1 \mathrm{mg}$. of depot-tetracosactrin the maximum mean plasma cortisol occurred at four hours and was then $6 \mu \mathrm{g} . / 100 \mathrm{ml}$. less than the maximum after 80 units of corticotrophin-gel, but this difference was not significant. Compared with the response to the gel, the mean concentration fell more slowly after the 1-mg. dose and reached basal values at between 32 and 48

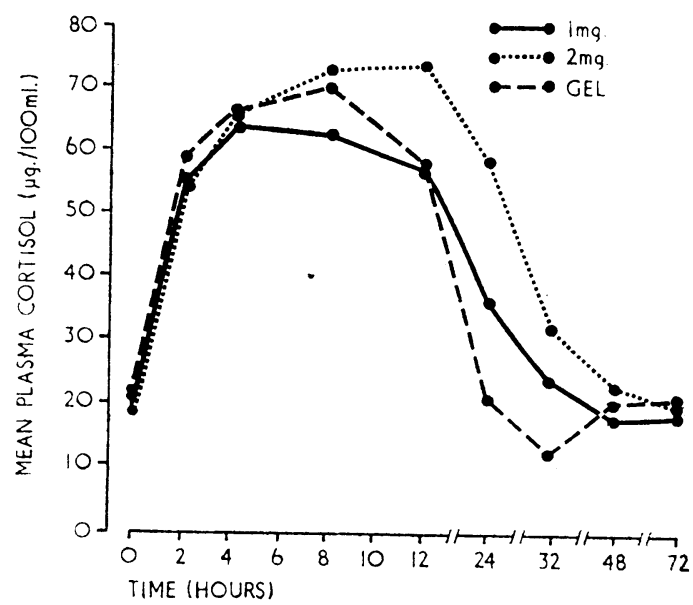

FIG. 1.- Mean plasma cortisol concentrations in 18 normal subjects after 80 units of corticotrophin-gel and 1 and $2 \mathrm{mg}$. of depot-tetracosactrin.

hours. The cortisol concentrations were significantly higher after $1 \mathrm{mg}$. than after the gel at 24 and 32 hours (see Table). After $2 \mathrm{mg}$. the maximum level was greater than after the gel or $1 \mathrm{mg}$. and remained higher from 4 to 48 hours, by which time it had just reached basal levels $(23 \mu \mathrm{g} . / 100 \mathrm{ml}$.). The differences from the levels after the gel were significant at 12 , 24 , and 32 hours and from the $1 \mathrm{mg}$. dose at $8,12,24$, and 32 hours (see Table).

\section{Corticosteroid-treated Patients (Fig. 2)}

The general pattern of effects was similar in this group. However, the maximum plasma cortisol levels achieved were virtually the same on all three treatments and were about $30 \mu \mathrm{g} . /$ $100 \mathrm{ml}$. (40\%) lower than in the normal subjects. Since these subjects' adrenal cortices were to a greater or less extent suppressed by the prednisolone treatment, the starting levels were low, but all three treatments provided a potent stimulus to the suppressed glands. In only 2 of the 12 subjects did the first treatment fail to raise the plasma cortisol above $25 \mu \mathrm{g} . /$ $100 \mathrm{ml}$. , and in these this level was achieved after the second treatment in one and after the third in the other. The mean plasma cortisol concentration after the 80 units of corticotrophin-gel at 24 hours $(27.5 \mu \mathrm{g} . / 100 \mathrm{ml}$.) was only just above the upper limit for the normal range at 9 a.m. $(6-26 \mu \mathrm{g} . /$ $100 \mathrm{ml}$.), whereas after the $1-\mathrm{mg}$. dose of the depot-tetra-

Probability Values for the Significance of the Differences Between the Mean Plasma-cortisol Levels after 80 Units Corticotrophin-gel and 1 and $2 \mathrm{mg}$. Depot-tetracosactrin in (a) 18 Normal Subjects and (b) 12 Corticosteroid-treated Patients

(a) Normal Subjects

\begin{tabular}{|c|c|c|c|c|c|c|c|c|c|}
\hline Time (hours): & 0 & 2 & 4 & 8 & 12 & 24 & 32 & 48 & 72 \\
\hline $\begin{array}{l}\text { Gel v. } 1 \text { mg. } \\
\text { Gel v. } 2 \text { " } \\
1 \text { mg. v. } 2 " \\
\text { S.E. of mean }\end{array}$ & $\begin{array}{c}\text { NS } \\
" \\
1 \cdot 42\end{array}$ & 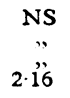 & $\begin{array}{c}\text { NS } \\
" \Rightarrow \\
2 \cdot 46\end{array}$ & $\begin{array}{l}\text { NS } \\
<0.05 \\
2 \cdot 78\end{array}$ & $\begin{array}{l}\text { NS } \\
<0.01 \\
<0.01 \\
3.47\end{array}$ & $\begin{array}{l}<0.01 \\
<0.001 \\
<0.001 \\
3.18\end{array}$ & $\begin{array}{l}<0.01 \\
<0.001 \\
<0.05 \\
2.56\end{array}$ & $\begin{array}{c}\text { NS } \\
\text { "’ } \\
1 \cdot 75\end{array}$ & $\begin{array}{c}\text { NS } \\
\text { "” } \\
0.90\end{array}$ \\
\hline
\end{tabular}

(b) Corticosteroid Patients

\begin{tabular}{|c|c|c|c|c|c|c|c|c|c|c|}
\hline \multicolumn{2}{|c|}{ Time (hours): } & 0 & 2 & 4 & 8 & 12 & 24 & 32 & 48 & 72 \\
\hline $\begin{array}{l}\text { Gel v. } 1 \text { mg. } \\
\text { Gel v. } 2 \text { " } 1 \text { mg. v. } 2 \text { ", }\end{array}$ & 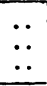 & $\begin{array}{c}\text { NS } \\
", \\
\end{array}$ & $\begin{array}{c}\text { NS } \\
", \\
\end{array}$ & $\begin{array}{c}\text { NS } \\
” \\
”\end{array}$ & $\begin{array}{c}\text { NS } \\
" \\
"\end{array}$ & $\begin{array}{c}\text { NS } \\
\ddot{~} \\
\end{array}$ & $\begin{array}{c}\text { NS } \\
<0.05 \\
\text { NS } \\
\end{array}$ & $\begin{array}{c}\text { NS } \\
<0.01 \\
<0.05 \\
\end{array}$ & $\begin{aligned} & N S \\
&< 0.01 \\
&< 0.01 \\
&\end{aligned}$ & $\begin{array}{c}\text { NS } \\
\ddot{\prime}\end{array}$ \\
\hline S.E. of mean & $\ldots$ & 1.43 & 2.82 & 4.69 & 4.50 & 3.69 & $3 \cdot 14$ & 3.72 & 3.23 & 1.65 \\
\hline
\end{tabular}


cosactrin it did not fall to this level until 32 hours, and after the 2-mg. dose until 48 hours. However, the concentrations after corticotrophin-gel and the 1-mg. dose were not signifi-

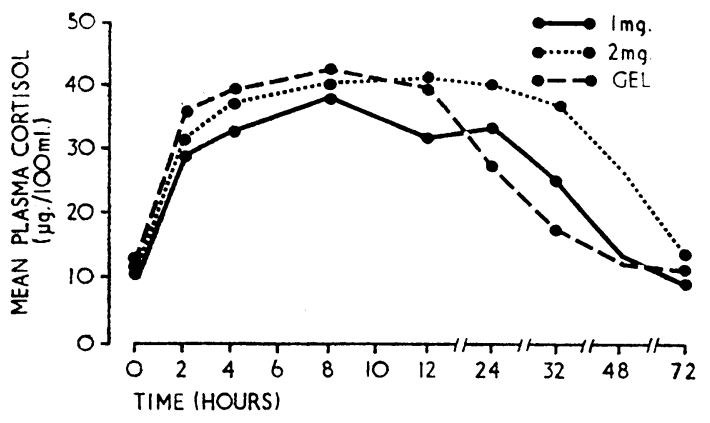

Fig. 2.- Mean plasma cortisol concentrations in 12 corticosteroid-treated patients after 80 units corticotrophingel and 1 and $2 \mathrm{mg}$. depot-tetracosactrin.

cantly different at any time, though they were significantly greater after the 2-mg. dose compared with the gel at 24, 32, and 48 hours, and compared with the 1-mg. dose at 32 and 48 hours (see Table).

\section{Corticotrophin-treated Patients (Fig. 3)}

In these six patients the pattern of results was similar to that of the normal subjects except that the maximum levels of cortisol achieved were some $10 \mu \mathrm{g} . / 100 \mathrm{ml}$. higher. In this small group the effect of the 1-mg. dose appeared to fall off more quickly than in the other groups, reaching $26 \mu \mathrm{g} . / 100 \mathrm{ml}$. at 24 hours.

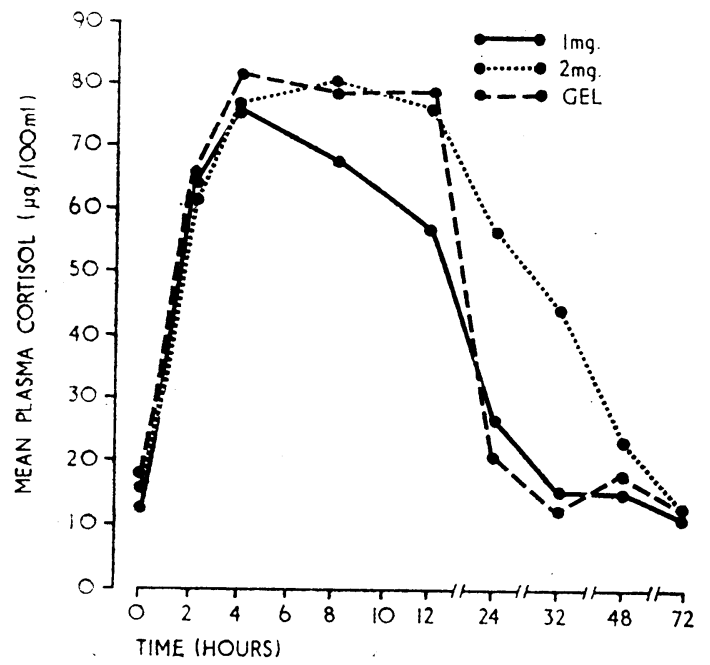

FIG. 3.- Mean plasma cortisol concentrations in sir corticotrophin-treated patients after 80 units corticotrophin-gel and 1 and $2 \mathrm{mg}$. depot-tetrasactrin.

\section{Clinical Features}

The depot-tetracosactrin is an aqueous suspension of $1 \mathrm{mg}$. of powder in $1 \mathrm{ml}$. and was simple to give, unlike the corticotrophin-gel, which was viscid and required preliminary warming. Thirteen out of 36 subjects complained of local discomfort after the depot-tetracosactrin, particularly when this was given into the deltoid muscle rather than into the thigh or buttock. Of these subjects, three also had discomfort after the gel.

Though not specifically investigated, it was apparent that in those subjects with asthma and rheumatoid arthritis given the depot-tetracosactrin for therapy symptoms were relieved within two to three hours and the clinical effect of $1 \mathrm{mg}$. lasted about 32 hours.

\section{Discussion}

The depot-tetracosactrin powerfully stimulated the adrenal cortex under normal conditions and also when suppressed by exogenous corticosteroids or stimulated by a previous course of corticotrophin. Since there were no differences between the $1-\mathrm{mg}$. dose, the 2-mg. dose, and the 80 units of corticotrophingel over the first four hours, it may be presumed that the gland was maximally stimulated over this time by each treatment. In terms of the maximum plasma cortisol concentration achieved, $1 \mathrm{mg}$. of the new drug was not significantly different from 80 units of corticotrophin-gel. The depot-tetracosactrin, however, maintained the plasma cortisol level for longer, and it may be concluded that to maintain a continuously elevated plasma cortisol $1 \mathrm{mg}$. of the synthetic agent need be given only once daily while the corticotrophin-gel in this dose must be given twice daily. Since the cortisol concentrations after $2 \mathrm{mg}$. were considerably, and significantly, higher than after $1 \mathrm{mg}$. up to 32 hours, alternate daily administration might be sufficient at this dose.

It is established that A.C.T.H. of animal origin may produce severe and sometimes fatal hypersensitivity reactions (Wilson, 1951 ; Hill and Swinburn, 1954 ; Inderbitzin, 1954 ; Pearson, 1959 ; Rajka, 1961 ; Forssman et al., 1963 ; Rosenblum and Rosenblum, 1964), though this must be a rare event with modern purified preparations. Jenny et al. (1963), Landon et al. (1964), and El-Shaboury (1965) challenged known corticotrophin-hypersensitive patients with the short-acting, unmodified tetracosactrin without producing hypersensitivity reactions, yet there was an adequate adrenocortical response in each case. However, the action of unmodified tetracosactrin is too short for practical therapy. The depot-preparation has a useful time course of action of 32 to 48 hours, and it is probable that at least a proportion of natural corticotrophin-hypersensitive patients could be treated with it.

Since stress-induced growth hormone release is inhibited by oral corticosteroids but not by corticotrophin (Frantz and Rabkin, 1964 ; Hartog et al., 1964 ; Friedman and Stimmler, 1966), corticotrophin therapy may be indicated rather than oral corticosteroids in children; there is evidence that "steroidstunting" is less likely to occur (Friedman and Strang, 1966 ; Friedman and Greenwood, 1967). Similarly, A.C.T.H. release in response to stress is less likely to be suppressed after corticotrophin therapy than after oral corticosteroids (Savage et al., 1962; Friedman and Greenwood, 1967). A complicating factor is the development of antibodies to the species-specific portion of the corticotrophin molecule in a high proportion of patients (Friedman and Greenwood, 1967) and sometimes acquired resistance to its adrenocorticotrophic action may develop (West, 1960, 1962). It is possible that corticotrophin of animal origin is more antigenic in man than the short-chain synthetic preparation containing the first 24 amino-acids of human corticotrophin in their natural sequence. The availability of a depot preparation of this synthetic tetracosactrin allows its antigenic potency to be tested in man, since it can be administered therapeutically on a long-term basis.

Bioassay initially showed that $1 \mathrm{mg}$. of tetracosactrin was equivalent to 106 units of animal corticotrophin (Schuler et al., 1963). This study has suggested that the modified depot preparation of this polypeptide is somewhat less potent, $1 \mathrm{mg}$. being approximately equal to 80 units of corticotrophin.

\section{Summary}

The adrenocorticotrophic action of a long-acting version of the synthetic polypeptide tetracosactrin has been compared in two doses ( 1 and $2 \mathrm{mg}$.) with 80 units of a gelatin preparation of natural corticotrophin in 18 normal subjects, 12 corticosteroid-treated patients, and six corticotrophin-treated patients over 72 hours. In terms of the mean maximum plasma cortisol 
concentrations attained $1 \mathrm{mg}$. of depot-tetracosactrin was approximately equivalent to 80 units of corticotrophin-gel. Mean plasma cortisol levels had returned to normal by 24 hours after the corticotrophin-gel, and by 48 hours after both doses of the depot tetracosactrin. To maintain a continuously elevated plasma cortisol corticotrophin-gel in this dose must be given twice daily and $1 \mathrm{mg}$. of the depot-tetracosactrin once daily; after $2 \mathrm{mg}$. alternate daily administration might be sufficient. All three preparations gave maximal adrenal cortical stimulation over the first four hours. The depot-tetracosactrin was simpler to give than the corticotrophin-gel. Local discomfort was more common after the synthetic preparation.

We are grateful to Professor E. F. Scowen and Dr. P. V. Cole for their interest and to the physicians of St. Bartholomew's Hospital and St. Leonard's Hospital for permission to study patients under their care. CIBA Laboratories kindly provided the depot-tetracosactrin, which is at present available only for clinical trial. We are particularly indebted to Miss Catherine Duncan for the statistical analysis.

\section{REFERENCES}

El-Shaboury, A. H. (1965). Lancet, 1, 298.

Forssman, O., Korsgren, M., Nordh, B., and Paulsen, F. (1963). Acta allerg. (Kbh.), 18, 462.
Frantz, A. G., and Rabkin, M. T. (1964). New Engl. F. Med., 271, 1375. Friedman, M., and Greenwood, F. C. (1967). Proc. roy. Soc. Med., 60, 910.

and Stimmler, L. (1966). Lancet, 2, 944.

- and Strang L. B. (1966). Ibid., 2, 568.

Hartley, H. O. (1955). Commun. Pure appl. Math., 8, 47.

Hartog, M., Gaafar, M. A., and Fraser. R. (1964). Lancet, 2, 376

Hill, B. H. R., and Swinburn, P. D. (1954). Ibid., 1, 1218.

Inderbitzin, T. (1954). Int. Arch. Allergy, 5, Suppl., p. 68.

Jenny, M., Muller, A. F., and Mach, R. S. (1963). Scheveis. med. Wschr., 93, 766

Landon, J., James, V. H. T. Cryer, R. J., Wynn, V., and Frankland, A. W. (1964). f. clin. Endocr., 24, 1206.

Mattingly, D. (1962). f. clin. Path., 15, 374.

Pearson, R. S. B. (1959). Postgrad. med. f., 35, 463.

Rajka, G. (1961). Acta allerg. (Kbh.), 16, 159.

Rosenblum, A. H., and Rosenblum, P. (1964). F. Pediat., 64, 387.

Savage, O., Copeman, W. S. C., Chapman, L., Wells, M. V., and Treadwell, B. L. J. (1962). Lancet, 1, 232.

Schuler, W., Schar, B., and Desaulles, P. (1963). Schweiz. med. Wschr., 93, 1027 .

Snedecor, G. W. (1956). Statistical Methods Applied to Experiments in Agriculture and Biology, 5th ed. Ames, Iowa.

West, H. F. (1960). Acta med. scand., 166, Suppl. No. 352. (1962). Ann. rheum. Dis., 21, 263.

Wilson, L. A. (1951). Lancet, 2, 478.

Wood, J. B., Frankland, A. W., James, V. H. T., and Landon, J. (1965). Ibid., 1, 243.

\title{
Simple Screening Test for Cushing's Syndrome
}

\author{
D. MATTINGLY,* M.B., M.R.C.P.; CHRISTINE TYLER, † B.SC., PH.D.
}

Cushing's syndrome is now generally recognized to be due to the prolonged excessive secretion of cortisol (hydrocortisone), and all of the main clinical features of this disorder have been accidentally reproduced at one time or another in patients on corticosteroid therapy. Gross cases may present no difficulty in diagnosis, but in recent years it has become apparent that these are in a minority, since adrenal hyperfunction is often present in patients with few signs and symptoms suggestive of classical Cushing's syndrome (Ross et al., 1966). Obesity is almost invariably present, but is of little diagnostic value because of its high incidence in the population as a whole, particularly in women between the ages of 20 and 50 years, who are the most likely to be suffering from Cushing's syndrome. Nevertheless, obesity is of some help in drawing attention to the possibility of this disease, and the suspicion of adrenocortical overactivity may be reinforced if the obesity is of central distribution and accompanied by hypertension, menstrual irregularities, hirsutism, or diabetes mellitus.

Clinical acumen, however, is insufficient to establish the diagnosis of this disease, and confirmation depends on showing that cortisol production is in excess of normal. The most reliable means of doing this is to measure the cortisol secretion rate by isotope dilution (Cope and Black, 1958 ; Brooks et al., 1963 ; Cope and Pearson, 1965 ; Ross et al., 1966). This technique has proved invaluable in equivocal cases, but is too highly specialized for routine clinical use. The same objection applies to the estimation of urinary cortisol excretion by chromatography, another procedure which has high diagnostic value (Cope and Black, 1959 ; Brooks et al., 1963 ; Rosner et al., 1963). At present most laboratories are only equipped to estimate urinary 17-oxogenic steroids or 17-hydroxycorticoids.

- Director, Postgraduate Medical Institute, University of Exeter. + Research Assistant, Postgraduate Medical Institute, University of Exeter.
It is now clear, however, that these levels often fall within the accepted normal range in patients with undoubted Cushing's syndrome, and so are an unreliable index of cortisol production in this disease. Indeed, Cope and Pearson (1965) have shown that there is no correlation between the cortisol secretion rate and 17-oxogenic steroid excretion over the normal range and the region just above it where so many of the equivocal values lie.

In order to recognize Cushing's syndrome in patients who are not yet grossly diseased, a test is needed the results of which more accurately reflect the cortisol secretion rate, and which is simple enough to be carried out routinely for screening purposes. In 1964 a simple fluorimetric method was described for estimating unconjugated 11-hvdroxvcorticoids in urine (Mattingly et al., 1964). These urinary 11-hydroxycorticoid estimations showed a better correlation with the cortisol secretion rate over the required range than did the 17-oxogenic steroids. Elevated levels were found in a number of patients with Cushing's syndrome, and it was suggested that this method might be of value in screening patients for this disease. The present paper extends these observations to include 34 patients with Cushing's syndrome, and compares their urinary 11-hydroxycorticoid excretion with that of control subjects and patients with "simple" obesity.

\section{Materials and Methods}

The ages of the subjects ranged from 13 to 72 years. They were divided into three groups:

(1) A control group consisting of 50 females and 59 males made up of normal subjects and of convalescent hospital patients. The latter were not acutely ill and were under no obvious stress at the 